\title{
Genital Chlamydia trachomatis infections in young adults - a school-based bio-behavioural study in urban areas, Poland, 2012 to 2015
}

Michal Czerwinski ${ }^{1}$, Marta Niedzwiedzka-Stadnik ${ }^{1}$, Anna Zielicka-Hardy ${ }^{1}$, Anna Tomusiak ${ }^{2}$, Malgorzata Sadkowska-Todys ${ }^{1}$, Andrzej Zielinski ${ }^{1}$, Magdalena Strus ${ }^{2}$, Piotr Heczko², Magdalena Rosinska ${ }^{1}$

1. Department of Epidemiology, National Institute of Public Health - National Institute of Hygiene, Warsaw, Poland

2. Department of Microbiology, Jagiellonian University Medical College, Krakow, Poland

Correspondence: Michal Czerwinski (mczerwinski@pzh.gov.pl)

Citation style for this article:

Czerwinski Michal, Niedzwiedzka-Stadnik Marta, Zielicka-Hardy Anna, Tomusiak Anna, Sadkowska-Todys Malgorzata, Zielinski Andrzej, Strus Magdalena, Heczko Piotr, Rosinska Magdalena. Genital Chlamydia trachomatis infections in young adults - a school-based bio-behavioural study in urban areas, Poland, 2012 to 2015. Euro Surveill. 2018;23(6):pii=17-00087. https://doi.org/10.2807/1560-7917.ES.2018.23.6.17-00087

Article submitted on 02 Feb 2017 / accepted on 04 Sep 2017 / published on 08 Feb 2018

Context and Aim: One of the most common sexually transmitted pathogens disproportionately affecting young people is Chlamydia trachomatis (CT). This study aimed to assess prevalence of CT among sexually active students (aged 18-19 years) in their final years of high school education in Warsaw and Krakow. Methods: The sample was selected from 61 clusters, each cluster representing one school. We described city, sex, type of school and their association with CT prevalence. To account for non-responders we applied inverse probability weighting. Results: Our study population consisted of 3,136 young adults eligible for CT screening, of whom 2,326 reported having had sexual intercourse within past 12 months. Of the 950 students who agreed to be tested, 39 were infected with CT. Weighted prevalence of CT was $3.9 \%(95 \%$ confidence interval (CI): 2.7-5.1); however, prevalence in the students in Warsaw $(6.6 \% ; 95 \% \mathrm{Cl}: 3.5-12.4)$ was six times higher (prevalence ratio $(P R)=5.9 ; 95 \%$ $\mathrm{Cl}: 2.0-17.3)$ than in Krakow (1.1\%; 95\% Cl: 0.5-2.6). In both settings, female students attending vocationaltechnical schools were most affected; the prevalence in this group was more than five times higher $(P R=5.2$; 95\% Cl:1.7-15.6) compared with female peers in high schools and more than three times higher $(P R=3.3$; 95\% Cl:1.0-10.7) compared with male peers attending vocational-technical schools. Conclusion: Our study suggested prevalence of CT infection among young people in Poland comparable with the European average, supporting implementation of a CT control programme as recommended in international guidelines.

\section{Introduction}

Infections caused by Chlamydia trachomatis (CT), with an estimated 131 million new cases worldwide each year, are among the most common sexually transmitted infections (STIs) [1]. Infection is often asymptomatic (75\% in women and $50 \%$ in men), delaying treatment and increasing the risk of developing long-term reproductive sequelae, such as infertility. Untreated CT infections may also promote transmission of human immunodeficiency virus (HIV) [2].

Sexually active young people are disproportionately affected by CT infection. In the European Union (EU), two thirds of all reported $\mathrm{CT}$ cases occur in people younger than 25 years [3].

Early age of first sex, frequent change of partners and not using barrier contraceptive methods (condoms) are some of the identified drivers of CT transmission among young people [4]. The availability of effective and affordable treatment calls for the development of targeted screening strategies to identify and stop the spread of the infection and avoid long-term health effects. In Poland, no national strategy for STI control or a specific CT screening programme are currently in place. Elements of STI/HIV control are incorporated by schools into general health education sessions, on a voluntarily basis.

Despite the clear vulnerability of adolescents and young adults to $\mathrm{CT}$, there are no comprehensive studies assessing this problem in Poland. Moreover, the majority of studies conducted to date have largely been based on adult patients actively seeking STI testing and/or treatment or visiting infertility clinics; consequently, they do not provide full insight into the prevalence of $\mathrm{CT}$, especially among adolescents in the general population $[5,6]$.

Our aim was to assess the prevalence of CT infection among sexually active young adults (aged 18-19 years) in their final years of high school education living in urban areas in Poland and to identify subgroups at 


\section{FIGURE 1}

Inclusion process, school-based bio-behavioural study on genital Chlamydia trachomatis infections, Poland, 2012$2015(\mathrm{n}=4,714)$

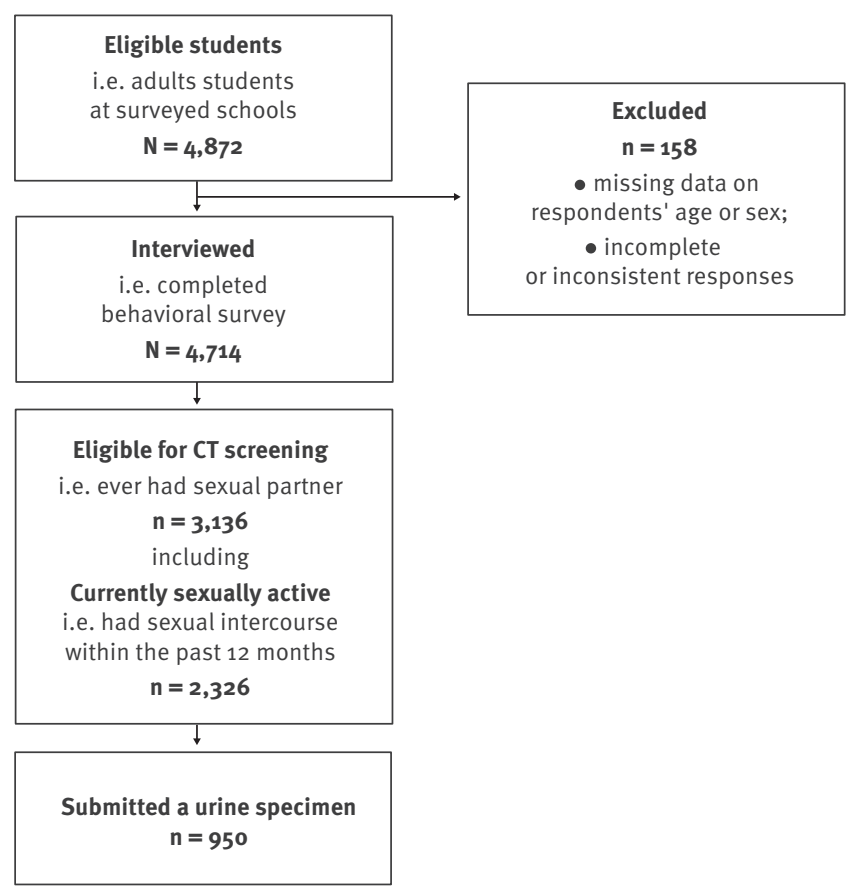

particular risk of infection in order to target interventions accordingly.

\section{Methods}

\section{Ethics statement}

The survey was designed for students 18 years and older based on their self-reported year of birth. Young people under the age of 18 years were not included in this study as, in Poland, this requires parental consent which may have decreased the likelihood of student participation. All research participants provided written consent. To ensure participants remained anonymous, each person was assigned a unique identification number which they could use to obtain their results. Those with a CT-positive test result were offered confidential advice and medical treatment at one of the collaborating STI clinics.

All study procedures were approved by the Institutional Review Board of the National Institute of Public Health - National Institute of Hygiene (NIPH-NIH), Warsaw, Poland.

\section{Study outline}

Between September 2012 and June 2015, a behavioural survey was conducted among students aged 18 years and older in their final years of secondary school education, in two of the biggest cities in Poland, Warsaw and Krakow. As ca $90 \%$ of 18-year-olds were enrolled in these schools, we did not sample young people who did not attend school.
The sample was selected using cluster sampling intending to include ca 60 schools (clusters) randomly drawn from all secondary schools registered in Warsaw and Krakow. Initially, we expected a 50\% response rate and additional schools were sampled, to account for lower response rate. In each cluster (school), all students 18 years and older were given CT awareness lectures during which they were invited to participate in a selfadministered behavioural survey. Awareness lectures were delivered by educators who routinely provide sexual health education for adolescents.

Subsequently, students eligible for CT screening (defined as those who had ever had a sexual partner, i.e. engaged in sexual intercourse or petting) were invited to provide urine samples for CT infection testing. The intended sample size for CT testing, assuming prevalence of infection was between $3 \%$ and $4.5 \%$, ranged from 527 to 1,145 individuals.

\section{Behavioural survey}

The main objective of the survey was to collect information on basic demographic data and risk factors associated with CT infection, including age at first sex, number and frequency of changing partners, condom use, symptoms of infection and previous history of STI infection or testing.

The questionnaire was designed by the Department of Epidemiology at the NIPH-NIH, using existing behavioural surveillance indicators and in consultation with sexual health educators. The questionnaire was pretested among 40 students in schools that were not selected to participate in this study, in order to assess the clarity of the questions and appropriateness of the language used.

\section{Urine sample collection for Chlamydia trachomatis screening}

During awareness raising sessions, all students who had ever had a sexual partner were offered an opportunity to get tested for CT. They received a sterile urine collection container and were asked to provide a $10 \mathrm{~mL}$ urine sample. Students who wanted to be tested were asked to collect their first stream of urine (containing mucus and epithelial cells) and return the container to the chlamydia screening team. After centrifugation (3,000 rpm, $30 \mathrm{~min})$, a pellet was collected and stored at $-20^{\circ} \mathrm{C}$.

\section{Laboratory testing}

Frozen urine specimens were transported to the Department of Microbiology at the Jagiellonian University Medical College in Krakow for CT testing by real-time nucleic acid amplification kit REALQUALITY RS-CHLAM T (AB Analitica, Padova, Italy) on an ABI 7500 real-time PCR system (Applied Biosystems, Foster City, California, United States). 


\section{FIGURE 2}

Factors influencing the submitting of a urine specimen, school-based bio-behavioural study on genital Chlamydia trachomatis infections, Poland, 2012-2015 $(\mathrm{n}=3,136)$

\begin{tabular}{|c|c|c|c|c|}
\hline Strata & $\begin{array}{c}\text { Factor } \\
\text { (comparison groups) }\end{array}$ & & & $\mathrm{aOR}(95 \% \mathrm{Cl})$ \\
\hline \multicolumn{5}{|c|}{ All sexually experienced } \\
\hline & Age $\geq 19$ vs 18 years & - & & $1.21(1.02-1.43)$ \\
\hline UTIs or gyn & cal symptoms (yes/no) & $\rightarrow-$ & & $1.85(1.55-2.22)$ \\
\hline \multicolumn{5}{|c|}{ Women only } \\
\hline Casual & e sex partners (yes/no) & 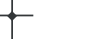 & & $0.99(0.76-1.30)$ \\
\hline \multicolumn{5}{|l|}{ Men only } \\
\hline Casual & e sex partners (yes/no) & & & $0.65(0.48-0.87)$ \\
\hline \multicolumn{5}{|c|}{ Having casual/multiple sex partners } \\
\hline & (Women vs men) & $\longrightarrow$ & & $1.89(1.32-2.70)$ \\
\hline \multicolumn{5}{|c|}{ No casual/multiple sex partners } \\
\hline & (Women vs men) & - & & $1.23(1.01-1.50)$ \\
\hline & o & 2 & 3 & \\
\hline
\end{tabular}

aOR: adjusted odds ratio; $\mathrm{Cl}$ : confidence interval; UTI: urinary tract infection.

\section{Statistical analysis}

\section{Chlamydia trachomatis prevalence}

CT prevalence was calculated among all participants eligible for CT screening. To obtain an estimate of CT prevalence that accounted for non-responders, we fitted a two-step inverse probability weighting (IPW) regression model $[7,8]$. The main purpose of IPW was to correct for the fact that some subgroups of sexually active students (at varying risks of CT infection) were more willing to take part in the study and submit a urine specimen. Applying individual weights to each survey respondent who submitted a urine specimen allowed us to calculate the CT prevalence estimates unaffected by selection bias.

Using logistic regression, we compared characteristics of sexually active respondents who participated in CT screening with those that did not. We modelled the probability of urine specimen submission as explained by known predictors of CT infection. Variables were entered into the model in a stepwise fashion using only those factors with a $\mathrm{p}$ value $\mathbf{0 . 2}$ in the univariate analysis.

In the next step, the inverse of the computed probabilities (after scaling) were applied as weights in multivariable log-binomial regression models used to estimate adjusted $\mathrm{CT}$ prevalence, prevalence ratios (PR) and their $95 \%$ confidence intervals $(95 \% \mathrm{Cl})$.

Two log-binomial regression models were carried out: one including students who had ever had a sexual partner and the second comprising only students who were currently sexually active (i.e. reported having had sexual intercourse within the past 12 months). The final models included the following terms: city, age, sex, type of school and an interaction term between sex and type of school. The second model included one additional factor: type of partners (one steady partner vs multiple or casual).

We assumed that adolescents who attended the same school over a long period of time may have shared beliefs, attitudes and knowledge regarding sexual behaviours and STI prevention, which may influence their STI risk. To account for this within-school correlation, we used the generalised estimating method with an independent correlation structure commonly used to analyse clustered data with a binary outcome. We report weighted adjusted CT prevalence estimated from the final log-binomial model, assuming the distribution of the explanatory variables as in the total population.

Sexual behaviours

To better understand differences in $\mathrm{CT}$ prevalence, we compared patterns of partnership in the 12 months preceding the survey and other factors associated with STI risk (e.g. condom use, availability of STI prevention education programmes at school) among currently sexually active respondents of the behavioural survey, by subpopulation defined by sex and school type. Specifically, recent sexual behaviours (in the 12 months before the interview) among female students in vocational-technical schools were compared with three other major groups of students (female students in high schools; male students in high schools; male students in vocational-technical schools) using Tukeytype adjustment for multiple comparisons [9]. Analysis was performed using SAS 9.3.

\section{Results}

\section{Selected schools}

During the study period, 206 schools (140 high schools and 66 vocational-technical schools) were randomly selected from a total of 432 secondary schools registered in Warsaw and Krakow and invited to participate in the study. Of these 206 schools invited, 61 (30\%) participated in the study; these were 38 schools officially classed as high schools and 23 vocational-technical schools. One of the participating high schools was privately owned.

Of the 145 schools that did not participate, 103 refused because of a timetable clash or the sensitive nature of our research topic. Forty-two schools were lost to follow-up or were unable to reach a final decision.

\section{Sample characteristics and predictors of participation in Chlamydia trachomatis screening}

Our study population comprised 4,714 young people aged 18 years and older of whom 2,768 were women 
Characteristics of the study population, school-based bio-behavioural study on genital Chlamydia trachomatis infections, Poland, 2012-2015 ( $\mathrm{n}=4,714)$

\begin{tabular}{|c|c|c|c|c|c|c|c|c|}
\hline \multirow{2}{*}{ Population by school type } & \multirow{2}{*}{ Stratum } & \multicolumn{2}{|c|}{ Krakow } & \multicolumn{2}{|c|}{ Warsaw } & \multirow{2}{*}{ p value } & \multicolumn{2}{|c|}{ Total } \\
\hline & & $\mathrm{n}$ & $\%$ & $\mathrm{n}$ & $\%$ & & $\mathrm{n}$ & $\%$ \\
\hline \multicolumn{9}{|c|}{ Total study population (all interviewed students) } \\
\hline \multirow{6}{*}{ All schools } & All & 2,204 & 100.0 & 2,510 & 100.0 & NA & 4,714 & 100.0 \\
\hline & Women & 1,356 & 61.5 & 1,412 & 56.3 & \multirow{2}{*}{0.0002} & 2,768 & 58.7 \\
\hline & Men & 848 & 38.5 & 1,098 & 43.7 & & 1,946 & 41.3 \\
\hline & 18 years & 698 & 31.7 & 1,239 & 49.4 & \multirow{3}{*}{$<.0001$} & 1,937 & 41.1 \\
\hline & 19 years & 1,160 & 52.6 & 1,043 & 41.6 & & 2,203 & 46.7 \\
\hline & 20 years and older & 346 & 15.7 & 228 & 9.1 & & 574 & 12.2 \\
\hline \multirow{2}{*}{ High school only } & Women & 496 & 22.5 & 1,259 & 50.2 & \multirow{4}{*}{$<.0001$} & 1,755 & 37.2 \\
\hline & Men & 283 & 12.8 & 793 & 31.6 & & 1,076 & 22.8 \\
\hline \multirow{2}{*}{ Vocational school only } & Women & 860 & 39.0 & 153 & 6.1 & & 1,013 & 21.5 \\
\hline & Men & 565 & 25.6 & 305 & 12.1 & & 870 & 18.5 \\
\hline \multicolumn{9}{|c|}{ Eligible for Chlamydia trachomatis screening (students, who had sexual intercourse or petting) } \\
\hline \multirow{6}{*}{ All schools } & All & 1,511 & 100.0 & 1,625 & 100.0 & NA & 3,136 & 100.0 \\
\hline & Women & 933 & 61.7 & 884 & 54.4 & \multirow{2}{*}{$<.0001$} & 1,817 & 57.9 \\
\hline & Men & 578 & 38.3 & 741 & 45.6 & & 1,319 & 42.1 \\
\hline & 18 years & 449 & 29.7 & 722 & 44.4 & \multirow{3}{*}{$<.0001$} & 1,171 & 37.3 \\
\hline & 19 years & 795 & 52.6 & 717 & 44.1 & & 1,512 & 48.2 \\
\hline & 20 years and older & 267 & 17.7 & 186 & 11.5 & & 453 & 14.5 \\
\hline \multirow{2}{*}{ High school only } & Women & 267 & 17.7 & 764 & 47.0 & \multirow{4}{*}{$<.0001$} & 1,031 & 32.9 \\
\hline & Men & 185 & 12.2 & 498 & 30.6 & & 683 & 21.8 \\
\hline \multirow{2}{*}{ Vocational school only } & Women & 666 & 44.1 & 120 & 7.4 & & 786 & 25.0 \\
\hline & Men & 393 & 26.0 & 243 & 15.0 & & 636 & 20.3 \\
\hline
\end{tabular}

NA: not applicable.

${ }^{a}$ Chi-squared tests of the difference in proportions.

and 1,946 were men (Figure 1). The mean age of respondents was 18.7 years.

Overall, 60\% $(n=2,831)$ of respondents were attending high schools and $40 \%(n=1,883)$ vocational-technical schools, however there were noticeable differences between the two cities (Table 1).

In total, 3,136 students reported having had a sexual partner in the past and were eligible for CT screening. Of these, $3 \%(n=97)$ reported ever having been tested for any STI in the past. Of the total 4,714 students who completed the questionnaire, $55 \%(n=2,613)$ reported having had sexual intercourse at least once, including 2,326 students who were currently sexually active (i.e. reported having had sexual intercourse within the past 12 months). This percentage was higher at vocationaltechnical schools $(67 \% ; n=1,260)$ compared with high schools $(48 \% ; n=1,353)$. Most respondents who had ever engaged in sexual intercourse were also sexually active in the previous 12 months ( $89 \% ; n=2,326)$.

Of 3,136 students eligible for CT screening, 950 submitted urine specimen adequate for testing; 711 of them were currently sexually active, including 703 students who provided information on the number and type (steady or casual) of their partners in the 12 months preceding the survey. Overall, women were more likely to participate in $\mathrm{CT}$ screening than men, particularly those who had reported engaging in sex with casual or multiple partners in past 12 months (Figure 2).

In the multivariate analysis (logistic regression), among all students (female and male combined), the odds of screening increased with the respondents' age (19 years and older vs 18 years) and current urogenital symptoms.

\section{Chlamydia trachomatis prevalence and related factors}

Of the 950 students tested, 39 were infected with CT. The weighted prevalence of CT calculated for all respondents eligible for CT screening was 3.9\% (95\% $\mathrm{Cl}: 2.7-5.1$ ); however, there were considerable differences in CT prevalence estimates depending on the city. The inverse probability-weighted and adjusted (for age, sex and type of school) CT prevalence estimated in the final log-binomial regression model for Warsaw (6.6\%; 95\% Cl:3.5-12.4) was approximately six times higher $(\mathrm{PR}=5.9 ; 95 \% \mathrm{Cl}: 2.0-17.3)$ than for Krakow (1.1\%; 95\% Cl: 0.5-2.6). 
TABLE 2

Overall and strata-specific inverse probability-weighted estimates of Chlamydia trachomatis prevalence among students, Poland, 2012-2015

\begin{tabular}{|c|c|c|c|c|c|}
\hline \multirow{2}{*}{ Population by school type } & \multirow{2}{*}{ Stratum } & \multicolumn{2}{|c|}{ CT prevalence ${ }^{a}$} & \multirow{2}{*}{$\frac{\text { Tested }}{n}$} & \multirow{2}{*}{$\frac{\text { CT-positive }}{n}$} \\
\hline & & $\%$ & $95 \% \mathrm{Cl}$ & & \\
\hline \multicolumn{6}{|c|}{ Eligible for CT screening (students, who had sexual intercourse or petting ever; $n=950$ ) } \\
\hline \multirow{7}{*}{ All schools } & Total & 3.9 & $2.7-5.1$ & 950 & 39 \\
\hline & Krakow & 1.1 & $0.5-2.6$ & 452 & 11 \\
\hline & Warsaw & 6.6 & $3.5-12.4$ & 498 & 28 \\
\hline & Women in Krakow & 1.4 & $0.6-3.0$ & 348 & 9 \\
\hline & Men in Krakow & 0.9 & $0.3-2.6$ & 104 & 2 \\
\hline & Women in Warsaw & 8.2 & $4 \cdot 3-15 \cdot 4$ & 287 & 17 \\
\hline & Men in Warsaw & $5 \cdot 4$ & $2.4-12.2$ & 211 & 11 \\
\hline \multirow{4}{*}{ High school only } & Women in Krakow & 0.6 & $0.2-2.1$ & 68 & 1 \\
\hline & Men in Krakow & 0.9 & $0.3-2.9$ & 45 & 1 \\
\hline & Women in Warsaw & 3.6 & $1.8-7.1$ & 254 & 9 \\
\hline & Men in Warsaw & 5.1 & $2.2-11.9$ & 133 & 6 \\
\hline \multirow{4}{*}{ Vocational school only } & Women in Krakow & 3.1 & $1.8-5.4$ & 280 & 8 \\
\hline & Men in Krakow & 1.0 & $0.3-3.2$ & 59 & 1 \\
\hline & Women in Warsaw & 18.6 & $7.0-49.3$ & 33 & 8 \\
\hline & Men in Warsaw & 5.6 & $1.8-17.9$ & 78 & 5 \\
\hline \multicolumn{6}{|c|}{ Currently sexually active only (students who had intercourse in past 12 months; $n=703$ ) } \\
\hline \multirow{4}{*}{ All schools } & Women with a one steady partner & 3.8 & $2.3-6.3$ & 377 & 18 \\
\hline & Women with a casual or multiple partners & 3.7 & $1.8-7.7$ & 106 & 6 \\
\hline & Men with a one steady partner & 1.7 & $0.7-4.2$ & 139 & 6 \\
\hline & Men with a casual or multiple partners & 1.7 & $0.6-5.0$ & 81 & 2 \\
\hline \multirow{4}{*}{ High school only } & Women with a one steady partner & 1.6 & $0.7-3.9$ & 157 & 6 \\
\hline & Women with a casual or multiple partners & 1.6 & $0.6-3.8$ & 73 & 3 \\
\hline & Men with a one steady partner & 1.7 & $0.6-5.0$ & 70 & 3 \\
\hline & Men with a casual or multiple partners & 1.7 & $0.6-5.6$ & 38 & 1 \\
\hline \multirow{4}{*}{ Vocational school only } & Women with a one steady partner & 9.0 & $5 \cdot 3-15.1$ & 220 & 12 \\
\hline & Women with a casual or multiple partners & 8.8 & $3.7-21.0$ & 33 & 3 \\
\hline & Men with a one steady partner & 1.7 & $0.6-5.5$ & 69 & 3 \\
\hline & Men with a casual or multiple partners & 1.7 & $0.4-6.5$ & 43 & 1 \\
\hline
\end{tabular}

CT: Chlamydia trachomatis.

a Inverse probability-weighted and adjusted CT prevalence estimated in the final log-binomial regression models. These models included the following terms: city, age, sex, type of school and an interaction term between sex and type of school. In addition, the second model (only students who were currently sexually active) included type of partner/s (one steady partner vs multiple or casual).

The most affected socio-demographic group in both settings were female students attending vocationaltechnical schools (Table 2). Weighted CT prevalence in this group (after adjustment for city and age), was more than five times higher $(P R=5.2 ; 95 \% \mathrm{Cl}: 1.7-15.6)$ than among female peers in high schools and more than three times higher $(\mathrm{PR}=3.3 ; 95 \% \mathrm{Cl}: 1.0-10.7)$ than among male peers attending vocational-technical schools. Among students attending high schools, however, similarly adjusted and weighted estimates of CT prevalence did not differ by sex.

CT prevalence calculated for currently sexually active students who reported one steady sex partner in the last year, was not statistically different from the prevalence noted among participants who reported casual or multiple partners ( $P R=1.0 ; 95 \% \mathrm{Cl}: 0.5-2.3$ ) (Table 2). Similarly, we did not find any association between CT prevalence and known risk factors for this infection such as early age (by 16 years) of first sex $(P R=1.2 ; 95 \% \mathrm{Cl}: 0.5-2.5)$ or oral contraceptive use $(\mathrm{PR}=0.8 ; 95 \% \mathrm{Cl}: 0.4-1.4)$.

\section{Sexual behaviours among currently sexually active students, by population group}

Overall, 2,326 respondents reported having had sexual intercourse in the previous 12 months. The majority of currently sexually active students $(76 \% ; n=1,775)$ reported only one sex partner within the past 12 months, women $(82 \% ; n=1,159)$ more so than men 


\section{TABLE 3}

Characteristics of currently sexually active ${ }^{\text {a }}$ women in vocational/technical schools compared with other groups of currently sexually active students, Poland, 2012-2015 $(\mathrm{n}=2,326)$

\begin{tabular}{|c|c|c|c|c|}
\hline \multirow{2}{*}{ School type } & \multirow{2}{*}{ Factor } & Women & Men & \multirow{2}{*}{$\begin{array}{c}\text { Chi-squared } \\
\text { p value }\end{array}$} \\
\hline & & $\%$ & $\%$ & \\
\hline \multicolumn{5}{|c|}{ Types of sex partners in the past 12 months } \\
\hline High school & \multirow{2}{*}{ One partner only, either steady or casual } & $78.8 *$ & $70.1 *$ & \multirow{2}{*}{$<0.0001$} \\
\hline Vocational school & & 86.7 (ref) & $63.9^{*}$ & \\
\hline High school & \multirow{2}{*}{ One steady partner only } & $76.7 *$ & 61.6 * & \multirow{2}{*}{$<0.0001$} \\
\hline Vocational school & & 86.4 (ref) & $57.1 *$ & \\
\hline High school & \multirow{2}{*}{ One casual partner only } & 2.1 * & 8.5 * & \multirow{2}{*}{$<0.0001$} \\
\hline Vocational school & & 0.3 (ref) & $6.7^{*}$ & \\
\hline High school & \multirow{2}{*}{$\begin{array}{l}\text { Multiple partners: only steady, only casual or both steady and } \\
\text { casual }\end{array}$} & $21.2 *$ & 29.9 * & \multirow{2}{*}{$<0.0001$} \\
\hline Vocational school & & 13.3 (ref) & $36.1 *$ & \\
\hline High school & \multirow{2}{*}{ Only steady multiple partners } & 4.6 & 4.1 & \multirow{2}{*}{$<0.0001$} \\
\hline Vocational school & & 4.6 (ref) & 10.2 * & \\
\hline High school & \multirow{2}{*}{ Only casual multiple partners } & $2.8 *$ & 11.4 * & \multirow{2}{*}{$<0.0001$} \\
\hline Vocational school & & 0.8 (ref) & $9.1 *$ & \\
\hline High school & \multirow{2}{*}{ Multiple partners, both steady and casual } & 13.8 * & $14 \cdot 4$ * & \multirow{2}{*}{$<0.0001$} \\
\hline Vocational school & & 7.9 (ref) & 16.9 * & \\
\hline \multicolumn{5}{|c|}{ Contraceptives in the past 12 months } \\
\hline High school & \multirow{2}{*}{ Condoms } & $74 \cdot 0$ & 80.2 * & \multirow{2}{*}{$<0.0001$} \\
\hline Vocational school & & 69.9 (ref) & 82.2 * & \\
\hline High school & \multirow{2}{*}{ Oral (hormonal) contraceptives } & 30.9 & 23.9 & \multirow{2}{*}{0.0062} \\
\hline Vocational school & & 27.6 (ref) & 22.6 & \\
\hline High school & \multirow{2}{*}{ Withdrawal (Coitus interruptus) } & 18.9 & 16.2 * & \multirow{2}{*}{0.0202} \\
\hline Vocational school & & 23.6 (ref) & 20.8 & \\
\hline High school & \multirow{2}{*}{ Natural methods } & 13.1 & 11.9 & \multirow{2}{*}{0.3314} \\
\hline Vocational school & & 10.0 (ref) & 12.6 & \\
\hline \multicolumn{5}{|l|}{ Other } \\
\hline High school & \multirow{2}{*}{ No STI education at school } & 47.2 * & 55.7 * & \multirow{2}{*}{$<0.0001$} \\
\hline Vocational school & & 67.2 (ref) & 69.7 & \\
\hline High school & \multirow{2}{*}{ Never used any sources of information on STI } & $24 \cdot 9^{*}$ & $34 \cdot 3^{*}$ & \\
\hline Vocational school & & 45.6 (ref) & $53 \cdot 3$ & 8.0001 \\
\hline
\end{tabular}

STI: sexually transmitted infection.

a Overall, 2,326 students reported sexual intercourse in the past 12 months before the interview, including 759 and 647 young women attending high schools and vocational schools, respectively, and 458 and 462 young men attending high schools and vocational schools, respectively.

* Indicates statistical significance ( $p<0.05$ after Tukey's multiple comparison adjustment) compared with female students in vocationaltechnical schools.

$(67 \% ; n=616)$ (Table 3). Among women, those attending vocational-technical schools differed significantly from the rest of the sample (i.e. from women in high schools, men in high schools and men in vocationaltechnical schools) with respect to the characteristics of their partners; they were more likely to report only one steady sexual partner in the previous 12 months and less likely to engage in casual sex.

Overall, $19 \%(n=166)$ of currently sexually active men and $28 \%(n=381)$ of the women reported never using a condom in the previous 12 months. Otherwise, men and women were similar in terms of contraceptive use. In addition, respondents with a steady partner more often used oral contraception $(P R=1.6 ; 95 \%$
$\mathrm{Cl}$ :1.2-2.1). Students using oral contraceptives, compared with those who did not, were almost three times less likely ( $P R=2.9 ; 95 \% \mathrm{Cl}: 2.5-3.3)$ to use condoms in the 12 months before interview.

Students attending vocational-technical schools were less exposed to STI prevention messages, be it at school $(\mathrm{PR}=1.4 ; 95 \% \mathrm{Cl}: 1.3-1.5)$ or through other sources such as parents, peers, Internet, radio, television and print media ( $P R=1.7 ; 95 \% \mathrm{Cl}: 1.5-1.9)$.

\section{Discussion}

To date, several population-based surveys focusing on CT in Western Europe have been published [10-12]. However, data from central-eastern and eastern Europe 
are limited [13]. Our study based on 4,714 young people attending secondary school was the first population-based CT bio-survey conducted in Poland to date. We evaluated prevalence of CT infection among sexually active students (18 years and older) in their final years of high school education $(n=3,136)$ in two of the biggest cities in Poland (Warsaw and Krakow), and identified high-prevalence subgroups who need sexual health intervention. Importantly, we collected extensive information on personal characteristics and STI risk factors from all study participants to control and adjust for non-participation in CT screening.

The weighted estimates of CT prevalence among all respondents eligible for CT screening varied considerably by city. The prevalence in Warsaw $(6.6 \% ; 95 \%$ $\mathrm{Cl}: 3 \cdot 5-12.4)$, even after adjustment for age, sex and type of school, was ca six times higher than in Krakow (1.1\%; 95\% Cl:0.5-2.6). Although the reasons for such heterogeneity are unclear, given the same study design and similar participation rates in both settings, they are likely to represent real differences in the local epidemiological profile. In line with our results, subnational CT prevalence estimates in other countries are also very heterogeneous even after controlling for variations in the study design. Recent sub-national estimates in high-income countries ranged from $0.6 \%$ to $10.7 \%$ among women and from $1.1 \%$ to $5.9 \%$ among men 25 years or younger [14].

In our sample, the socio-demographic group with the highest prevalence of CT both in Warsaw and in Krakow were female students attending vocational-technical schools. The prevalence estimates for this group were more than five times higher than for female peers in high-schools, and more than three times higher than for male peers attending vocational-technical schools. Recent research links pockets of higher STI incidence among adolescents to certain social determinants of health, in particular low socio-economic status and limited access to health promotion or healthcare $[10,15]$. These results may be relevant for our study population. The choice of secondary high school track (vocational vs general education) is indeed strongly related to family background $[16,17]$. Consequently, the average socio-economic status of students at vocational-technical schools' is likely to be lower compared with those attending general education schools [18].

We hypothesise that the higher prevalence of CT observed in vocational-technical schools reflects socio-economic differences as well as access to certain health services. Indeed, our data confirm that students attending vocational-technical schools were less exposed to STI prevention messages, be it at school or through other sources (i.e. parents, peers, Internet, radio, television and print media). The high prevalence of $C T$ infections in this subgroup was unexpected, as female students in our sample who attended vocational-technical schools reported more commonly than other groups that they were in stable relationships.
These students were more likely to engage in sexual intercourse with only one steady partner and overall less likely to report partner change.

It is worth noting, that in our sample, CT prevalence among respondents who reported only one steady partner in the last year was not statistically different from the prevalence among participants who reported one recent casual or multiple sex partners. These findings differed from research conducted in other countries where, age aside, the number of sexual partners was the only consistent risk factor for CT infection $[19,20]$. We note, however, that the majority of our respondents reported only one sex partner in the past year and we were not able to stratify the analysis by other important factors, i.e. condom use or age at first sex. Having casual/multiple partners could have been confounded by more consistent use of condoms [20]. It is also possible that some respondents were at increased risk for infection because of the behaviours associated with having steady partner. In our study, a steady partner was a significant predictor of oral contraceptive use. Moreover, couples using hormonal contraceptives were much less likely than non-users to have used condoms in the 12 months before the interview. Previous research has suggested that users of hormonal contraceptives may be at increased risk of acquiring STIs, although such association has not been observed in population-based studies [21,22]. Reduced use of condoms is, however, consistently associated with increased risk of STIs. Our finding also suggests, in line with previous studies, that large number of adolescents are more concerned about preventing unwanted pregnancies than STIs $[23,24]$.

The study of sexual behaviour patterns is complex and, as demonstrated in this study, the effect of any specific risks may be confounded by other factors, making it difficult to base screening on risk assessment. For this reason, other studies such as one recently conducted in England, have not found an association of CT positivity rate with any of sexual behaviour variables [25].

Our study could be used as a platform to debate the implementation of a national STI control programme in which CT screening would form a key component. Opportunistic screening targeting, in the first instance, young women would be of benefit. In Poland, the coverage of STI programmes in school settings is extremely low and a large proportion of our respondents highlighted that they had no access to further information and resources on STI. According to guidelines from the European Centre for Disease Prevention and Control (ECDC) [26], such interventions should as a minimum include education for young people and case management with contact tracing.

\section{Limitations}

Finding from this study may be limited due to participation bias, as we were only able to include $30 \%$ 
of invited sexually active students. Furthermore, our sample did not include a sufficient number of students attending private secondary schools, which prevents any extrapolation of the results to this small segment of the population (ca $6 \%$ of adolescents attend private secondary schools in the two cities).

The acceptance rate in our study was comparable to those reported in some school-based chlamydia screening programmes [27] but lower than in others [28]. Although our prevalence estimates were adjusted (IPW) for relevant factors associated with participation in CT screening, we note that surveys with lower response rates tend to produce higher estimates [1]. This is because participants in STI screening programmes usually have stronger risk factors related to STI risk than non-participants. The adjustment in our study allowed correction for a possible impact of the measured factors (i.e. age, sex, casual/multiple sexual partners, current UTI or gynaecological symptoms). Although we assessed similar predictors as reported in the literature [29], we recognise that additional predictors of participation may exist which were not accounted for.

Recent testing for CT was not likely to impact participation as only $3 \%$ of the participating and non-participating groups reported any STI test in the past. We therefore do not expect a large bias, despite the low response rate.

In addition, we detected only 39 CT infections, which limited our ability to conduct further analysis on risk factors for $\mathrm{CT}$ infection. We therefore analysed baseline data collected to control and adjust for non-participation in CT screening rather than examining subtle differences in behavioural risks. As a result, some social and behavioural variables which might have provided us with insight into the nature of excess risk for CT infection among adolescents were not available. This included patterns of partnership (e.g. having partners from or outside the school or having much older sex partners) or the students' socio-economic status.

\section{Conclusions}

This study suggests a prevalence of CT infection among young adults attending school in large Polish cities that is comparable to the European average and advocates the development of a CT control programme as recommended in ECDC guidelines. Our findings support the implementation of the key elements of these guidelines, e.g. sexual education and opportunistic screening, targeting the most vulnerable and underserved groups.

Our data suggest that female students attending vocational-technical schools in Poland, despite being the smallest group in our study, are at increased risk of CT. Generally, we note that the adolescents attending vocational schools have less access to sexual education and would benefit from targeted interventions to facilitate early detection of undiagnosed infection. More importantly, our findings confirmed that having only one steady partner in the recent year does not eliminate the risk for CT infection. Therefore, it should be recommended that clinicians offer routine screening and an STI consultation and advice to sexually active young women irrespective of their reported partner history. Universal educational programmes for secondary school students should be implemented in order to increase awareness and promote good sexual health.

\section{Acknowledgements}

This work was fully supported by the National Science Center, Poland, Research Grant NCN 2011/01/B/NZ7/04651.

The authors thank the teachers and students of all participating schools. We are also grateful to Prof Maria Gańczak and Prof Justyna Kowalska for useful comments on an earlier version of the paper.

\section{Conflict of interest}

None declared.

Authors' contributions

Wrote the paper: MC, MR. Analysed the data: MC, MR. Conducted laboratory testing: AT, MS, PH. Critically reviewed the manuscript: MNS, AZH, AT, MST, AZ, MS, PH. Conceived and designed the study: $\mathrm{PH}, \mathrm{AZ}, \mathrm{MST}, \mathrm{AZH}$.

\section{References}

1. Newman L, Rowley J, Vander Hoorn S, Wijesooriya NS, Unemo M, Low N, et al. Global estimates of the prevalence and incidence of four curable sexually transmitted infections in 2012 based on systematic review and global reporting. PLoS One. 2015;10(12):e0143304. https://doi.org/10.1371/journal. pone.0143304 PMID: 26646541

2. Fleming DT, Wasserheit JN. From epidemiological synergy to public health policy and practice: the contribution of other sexually transmitted diseases to sexual transmission of HIV infection. Sex Transm Infect. 1999;75(1):3-17. https://doi. org/10.1136/sti.75.1.3 PMID: 10448335

3. European Centre for Disease Prevention and Control (ECDC). Sexually transmitted infections in Europe 2013. Stockholm: ECDC; 2015. Available from: https://ecdc.europa.eu/sites/ portal/files/media/en/publications/Publications/sexualtransmitted-infections-europe-surveillance-report-2013.pdf

4. Eaton DK, Kann L, Kinchen S, Shanklin S, Flint KH, Hawkins J, et al. Youth risk behavior surveillance - United States, 2011. MMWR Surveill Summ. 2012;61(4):1-162. PMID: 22673000

5. Choroszy-Król I, Murawski M, Pawlik L, Teryks-Wołyniec $D$, Frej-Mądrzak M. Incidence of chlamydial uterine cervix infections in south-west Poland in the period of 1996-2004. Adv Clin Exp Med. 2006;15(3):427-33.

6. Frej-Mądrzak M, Teryks-Wołyniec D, Jama-Kmiecik A, Sarowska J, Choroszy-Król I. Diagnosing Chlamydia trachomatis urinary tract infections--preliminary report. Adv Clin Exp Med. 2015;24(3):441-5. https://doi.org/10.17219/acem/43719 PMID: 26467132

7. Brick JM. Unit nonresponse and weighting adjustments: a critical review. J Off Stat. 2013;29(3):329-53. https://doi. org/10.2478/jos-2013-0026

8. Seaman SR, White IR. Review of inverse probability weighting for dealing with missing data. Stat Methods Med Res. 2013;22(3):278-95. https://doi. org/10.1177/0962280210395740 PMID: 21220355

9. Elliott AC, Reisch JS. Implementing a multiple comparison test for proportions in a 2 xc crosstabulation in SAS. Dallas: SUGI (SAS Global Users Group) conference; 26-29 Mar 2016; 
San Francisco, US. Available from: http://www2.sas.com/ proceedings/sugi31/204-31.pdf

10. Haar K, Bremer V, Houareau C, Meyer T, Desai S, Thamm $M$, et al. Risk factors for Chlamydia trachomatis infection in adolescents: results from a representative populationbased survey in Germany, 2003-2006. Euro Surveill. 2013;18(34):20562. https://doi.org/10.2807/1560-7917. ES2013.18.34.20562 PMID: 23987832

11. van Bergen J, Götz HM, Richardus JH, Hoebe CJ, Broer J, Coenen AJ, et al. Prevalence of urogenital Chlamydia trachomatis increases significantly with level of urbanisation and suggests targeted screening approaches: results from the first national population based study in the Netherlands. Sex Transm Infect. 2005;81(1):17-23. https://doi.org/10.1136/sti.2004.010173 PMID: 15681716

12. Goulet V, de Barbeyrac B, Raherison S, Prudhomme M, Semaille C, Warszawski J, et al. ; Prevalence of Chlamydia trachomatis: results from the first national population-based survey in France. Sex Transm Infect. 2010;86(4):263-70. https://doi.org/10.1136/sti.2009.038752 PMID: 20660590

13. Uusküla A, Kals M, Denks K, Nurm U, Kasesalu L, Dehovitz J, et al. The prevalence of chlamydial infection in Estonia: a population-based survey. Int J STD AIDS. 2008;19(7):455-8. https://doi.org/10.1258/ijsa.2008.007325 PMID: 18574116

14. Redmond SM, Alexander-Kisslig K, Woodhall SC, van den Broek IV, van Bergen J, Ward H, et al. Genital chlamydia prevalence in Europe and non-European high income countries: systematic review and meta-analysis. PLoS One. 2015;10(1):eo115753. https://doi.org/10.1371/journal.pone.0115753 PMID: 25615574

15. Hardwick D, Patychuk D. Geographic mapping demonstrates the association between social inequality, teen births and STDs among youth. Can J Hum Sex. 1999;8(2):77-90.

16. Dustmann C. Parental background, secondary school track choice, and wages. Oxf Econ Pap. 2004;56(2):209-30. https:// doi.org/10.1093/oep/gpfo48

17. Putkiewicz E, Zahorska M. Społeczne nierówności edukacyjne - studium sześciu gmin. [Social inequalities in education - a study of 6 municipalities]. Warsaw: Institute of Public Affairs; 2001. Polish.

18. World Health Organization Regional Office for Europe (WHO/ Europe). Social inequalities in health in Poland. Copenhagen: WHO/Europe; 2012. Available from: http://apps.who.int/iris/ bitstream/10665/107306/1/E96720.pdf

19. Skjeldestad FE, Marsico MA, Sings HL, Nordbø SA, Størvold G. Incidence and risk factors for genital Chlamydia trachomatis infection: a 4-year prospective cohort study. Sex Transm Dis. 2009;36(5):273-9. https://doi.org/10.1097/ OLQ.ob013e3181924386 PMID: 19265733

20. Sonnenberg P, Clifton S, Beddows S, Field N, Soldan K, Tanton $C$, et al. Prevalence, risk factors, and uptake of interventions for sexually transmitted infections in Britain: findings from the National Surveys of Sexual Attitudes and Lifestyles (Natsal). Lancet. 2013;382(9907):1795-806. https://doi.org/10.1016/ S0140-6736(13)61947-9 PMID: 24286785

21. Mohllajee AP, Curtis KM, Martins SL, Peterson HB. Hormonal contraceptive use and risk of sexually transmitted infections: a systematic review. Contraception. 2006;73(2):154-65. https:// doi.org/10.1016/j.contraception.2005.08.012 PMID: 16413846

22. Torrone E, Papp J, Weinstock HCenters for Disease Control and Prevention (CDC). Prevalence of Chlamydia trachomatis genital infection among persons aged 14-39 years--United States, 2007-2012. MMWR Morb Mortal Wkly Rep. 2014;63(38):834-8. PMID: 25254560

23. Abel G, Brunton C. Young people's use of condoms and their perceived vulnerability to sexually transmitted infections. Aust N Z J Public Health. 2005;29(3):254-60. https://doi. org/10.1111/j.1467-842X.2005.tbo0764.x PMID: 15991774

24. Matteelli A, Capelli M, Sulis G, Toninelli G, Carvalho ACC, Pecorelli S, et al. Prevalence of Chlamydia trachomatis and Neisseria gonorrhoeae infection in adolescents in Northern Italy: an observational school-based study. BMC Public Health. 2016;16(1):200. https://doi.org/10.1186/s12889-016-2839-x PMID: 26927226

25. Syred J, Engler B, Campbell L, Baraitser P, Sheringham J. Exploration of gender differences of Chlamydia trachomatis infection amongst young people reveals limitations of using sexual histories to assess risk in high-prevalence areas. Int J STD AIDS. 2014;25(8):564-70. https://doi. org/10.1177/0956462413515451 PMID: 24352135

26. European Centre for Disease Prevention and Control (ECDC). Guidance on chlamydia control in Europe - 2015. Stockholm: ECDC; 2016. Available from: https://ecdc.europa.eu/sites/ portal/files/media/en/publications/Publications/chlamydiacontrol-europe-guidance.pdf

27. Božičević I, Grgić I, Židovec-Lepej S, Čakalo JI, Belak-Kovačević S, Štulhofer A, et al. Urine-based testing for Chlamydia trachomatis among young adults in a population-based survey in Croatia: feasibility and prevalence. BMC Public Health. 2011;11(1):230. https://doi.org/10.1186/1471-2458-11-230 PMID: 21489313

28. Matteelli A, Capelli M, Sulis G, Toninelli G, Carvalho ACC, Pecorelli S, et al. Prevalence of Chlamydia trachomatis and Neisseria gonorrhoeae infection in adolescents in Northern Italy: an observational school-based study. BMC Public Health. 2016;16(1):200. https://doi.org/10.1186/s12889-016-2839-x PMID: 26927226

29. Gravningen K, Simonsen GS, Furberg AS, Wilsgaard T. Factors associated with Chlamydia trachomatis testing in a high school based screening and previously in clinical practice: a crosssectional study in Norway. BMC Infect Dis. 2013;13(1):361. https://doi.org/10.1186/1471-2334-13-361 PMID: 23915415

\section{License and copyright}

This is an open-access article distributed under the terms of the Creative Commons Attribution (CC BY 4.0) Licence. You may share and adapt the material, but must give appropriate credit to the source, provide a link to the licence, and indicate if changes were made.

This article is copyright of the authors, 2018. 